\title{
Expanding public health professionals' roles in promoting and supporting breastfeeding as optimal infant feeding: A pilot study with online tutorial implications
}

\author{
Amna Umer ${ }^{1^{*}}$, Roger A. Edwards ${ }^{1,2}$ \\ ${ }^{1}$ Department of Health Sciences, Bouvé College of Health Sciences, Northeastern University, Boston, USA; \\ *Corresponding Author: amnaumer@gmail.com \\ ${ }^{2}$ Department of Pharmacy Practice, School of Pharmacy, Bouvé College of Health Sciences, Northeastern University, Boston, USA; \\ ro.edwards@neu.edu
}

Received 17 January 2013; revised 10 March 2013; accepted 14 April 2013

Copyright (c) 2013 Amna Umer, Roger Edwards. This is an open access article distributed under the Creative Commons Attribution License, which permits unrestricted use, distribution, and reproduction in any medium, provided the original work is properly cited.

\section{ABSTRACT}

Background: Their knowledge of preventive health, coupled with their dynamic roles in the community, puts public health professionals in a key position to expand their roles in the health promotion and support of breastfeeding as optimal infant feeding. This online tutorial was created to increase public health professionals' knowledge about breastfeeding and to assess their attitudes in supporting healthy behaviors related to infant feeding as a health promotion strategy. Method: The study utilized an online breastfeeding tutorial based on the US Breastfeeding Committee recommendations for minimum breastfeeding knowledge for health professionals. Pre- and post-tutorial questionnaires assessed breastfeeding knowledge, and an attitudinal survey evaluated attitudes of public health professionals after the tutorial. Exposing public health students to this information can facilitate the early shaping of their attitudes and understanding about the importance of breastfeeding. Results: Fifty-two Northeastern University MPH students and alumni $(62 \%$ response rate) completed the study. There was an overall gain in participants' fundamental knowledge regarding breastfeeding as assessed by pre- $(77 \%)$ to post-tutorial $(97 \%)$ correct responses $(p=$ 0.00001 ). The post-tutorial attitudinal survey showed that $92 \%$ of participants were comfortable in answering questions about breastfeeding as part of their professional responsibilities.
Conclusion: This pilot study highlights the important role that a short online tutorial can play in expanding public health professionals' knowledge about breastfeeding. Greater use of online methods can enhance awareness of critical health behaviors, such as breastfeeding, that have not received adequate attention in public health curricula. This pilot study provides the foundation for a larger study. Integration of breastfeeding into public health professionals' core training could support broader social change.

Keywords: Breastfeeding; Health Promotion; Public Health; Online Tutorial

\section{INTRODUCTION}

Breastfeeding and human milk is not only the most optimum form of nutrition for infants [1] but also the most superior form of feeding for babies [2]. The constituents of human milk are specifically intended for human babies and any other form of feeding preparations is markedly different from human milk [2]. The American Academy of Pediatrics recently published a policy statement and concluded, "infant feeding should not be considered as a lifestyle choice but rather as a basic health issue" [3].

Improving rates of breastfeeding would significantly improve public health [1] as extensive research has documented numerous benefits of breastfeeding ranging from healthy individuals to healthy families and society $[4,5]$. It promotes health and prevents disease in the short and long term for both infants and mothers [6]. In 2007, 
the Agency for Healthcare Research and Quality (AHRQ) published a summary of systematic reviews and metaanalyses of more than 9000 publications on breastfeeding and maternal and infant health outcomes in developed countries. The AHRQ concluded that breastfeeding is associated with a reduced risk of many diseases in infants and mothers from developed countries [1,7]. The report showed a reduction in acute otitis media, nonspecific gastroenteritis, severe lower respiratory tract infections, atopic dermatitis, asthma, obesity, type 1 and 2 diabetes, childhood leukemia, sudden infant death syndrome, and necrotizing enterocolitis in breastfed infants. The report also showed that mothers who breastfed had a reduced incidence of type 2 diabetes and breast and ovarian cancer, and a reduced risk of maternal post-partum depression [1,7]. Table 1 summarizes the AHRQ report findings for infants and mothers.

The use of human milk for infant feeding is an important public health topic and a target of health education and promotion programs throughout the world [8]. Dr. David Meyers, Director of the Center for Primary Care at the AHRQ described breastfeeding as, "an amazingly complex and incredibly adaptive system. Breastfeeding represents an intricate process of interaction between mother and infant that is far more than nutrition; it is creating a new person: immune system, brain function, socialization, and long-term health [9].”

The American Academy of Pediatrics (AAP) has recommended exclusive breastfeeding during the first six months of life to achieve optimal growth, development and health of the child [10]. The AAP guidelines on breastfeeding further recommend a continuation of breast milk as the main source of nutrition for the second six months in infancy along with solid food intake [10]. The World Health Organization documents significant health and developmental benefits of breastfeeding for the first two years of life [11,12].

Even though breastfeeding is the recommended form of feeding infants for the first six months, only a small percentage of infants in the United States (US) are breastfed exclusively for this time period $[2,10,13]$. According to the most recent data from the US Centers for Disease Control and Prevention (CDC) National Immunization Survey, while $76.9 \%$ of new mothers initiate breastfeeding in the US, only $16.3 \%$ of these mothers breastfeed exclusively for the first six months and only 25.5\% continue some breastfeeding to one year [14]. Compared to Europe, Australia, and Canada, the US has the lowest rate of breastfeeding initiation and the lowest rate of breastfeeding at six months. [15]. The US Department of Health and Human Services recently launched the Healthy People 2020 objectives that aim to raise the existing practices for breastfeeding in the US as shown in Table 2 [16].
Table 1. Health benefits of breastfeeding for the infant and mother from AHRQ evidence report.

\begin{tabular}{|c|c|c|}
\hline $\begin{array}{l}\text { Health benefits of } \\
\text { breastfeeding }\end{array}$ & $\mathrm{OR} / \mathrm{RR} / \mathrm{HR}^{*}$ & $\begin{array}{l}\text { 95\% Confidence } \\
\text { interval }\end{array}$ \\
\hline \multicolumn{3}{|l|}{ INFANT } \\
\hline Otitis media & OR 0.60 & $0.46-0.78$ \\
\hline Gastroenteritis & OR 0.36 & $0.32-0.41$ \\
\hline Diarrhea & OR 0.36 & $0.18-0.74$ \\
\hline $\begin{array}{l}\text { Severe lower respiratory } \\
\text { tract infections }\end{array}$ & RR 0.28 & $0.14-0.54$ \\
\hline Atopic dermatitis & OR 0.78 & $0.62-0.99$ \\
\hline Asthma & OR 0.70 & $0.60-0.81$ \\
\hline Obesity & OR 0.76 & $0.67-0.86$ \\
\hline $\begin{array}{c}\text { Type } 1 \text { diabetes (if never } \\
\text { breastfed) }\end{array}$ & OR 1.13 & $1.04-1.23$ \\
\hline Type 2 diabetes & OR 0.61 & $0.44-0.85$ \\
\hline Childhood leukemia & OR 0.80 & $0.71-0.91$ \\
\hline $\begin{array}{l}\text { Sudden infant death } \\
\text { syndrome (SIDS) }\end{array}$ & OR 0.64 & $0.51-0.81$ \\
\hline $\begin{array}{l}\text { Necrotizing enterocolitis } \\
\text { (NEC) }\end{array}$ & RR 0.42 & $0.18-0.96$ \\
\hline \multicolumn{3}{|l|}{ MOTHER } \\
\hline Type 2 diabetes & HR 0.63 & $0.54-0.73$ \\
\hline Breast Cancer & OR 0.84 & $0.78-0.91$ \\
\hline Ovarian cancer & OR 0.79 & $0.68-0.91$ \\
\hline $\begin{array}{l}\text { Postpartum depression } \\
\text { (if did not breastfeed) }\end{array}$ & HR 1.25 & $1.03-1.52$ \\
\hline
\end{tabular}

* OR = odds ratio; $\mathrm{RR}$ = risk ratio; $\mathrm{HR}$ = hazard ratio.

Healthcare service providers have key educational and supportive roles to inform mothers about initiation and continuation of breastfeeding [17]. Despite these important roles, health professionals' knowledge and their support for breastfeeding are generally lacking [17] and a challenge that spans many countries, cultures, and socioeconomic backgrounds [18]. Mothers continue to experience conflicting and inaccurate advice, invasive assistance, insufficient postnatal staffing, and sometimes even discouraged to breastfeed $[19,20]$. Health care professionals can make an important contribution to the promotion of breastfeeding through encouragement, recommendations, and role modeling [20].

A review of the literature revealed a scarcity of information on public health professionals' knowledge of infant feeding guidelines, which suggests that this topic is not adequately addressed within public health education. Exposing public health students to general breastfeeding information would facilitate the early shaping of their 
Table 2. Healthy People 2020 Objectives related to Breastfeeding.

\begin{tabular}{cc}
\hline \multicolumn{1}{c}{ Objective } & $\begin{array}{c}2020 \\
\text { Target } \%\end{array}$ \\
\hline $\begin{array}{c}\text { Encrease the proportion of infants who are } \\
\text { breastfed: } \\
\text { At } 6 \text { months }\end{array}$ & 81.9 \\
At 1 year & 60.6 \\
Exclusively through 3 months & 34.1 \\
Exclusively through 6 months & 46.2 \\
Increase the proportion of employers that have \\
worksite lactation support programs \\
$\begin{array}{l}\text { Reduce the proportion of breastfed newborns } \\
\text { who receive formula supplementation within } \\
\text { the first 2 days of life }\end{array}$
\end{tabular}

attitudes, understanding, and behaviors around breastfeeding. As little is known about public health professionals' knowledge about infant feeding practices, it is important not only to assess their current knowledge on the subject but also assess their attitudes in order to systematically identify learning gaps and improve the breastfeeding education programs and practices of public health professionals [17].

In an effort to explore this issue, we created and pilottested an online tutorial for Masters of Public Health (MPH) students and alumni at Northeastern University. We used this method as web-based health education has been proven to be an effective way to increase knowledge and promote positive health behaviors of participants compared to traditional methods [21,22].

The objective of this research project was to assess and improve participants' knowledge regarding infant feeding and to assess the attitudes of public health professionals regarding their roles in encouraging breastfeeding as the main form of infant feeding in their communities. The study also sought to explore how public health professionals might broaden their roles in supporting healthy behaviors related to infant feeding.

\section{METHOD}

We created an online tutorial, knowledge pre-test and post-test questionnaires, and an attitudinal survey to be administered to all public health students and alumni at Northeastern University's MPH program (since its inception in 2008). The brief 15-minute online tutorial provided MPH students and alumni with general information on the health benefits of human milk and on evi- dence-based guidelines related to breastfeeding and its contraindications. The tutorial was based on the minimum breastfeeding knowledge for health professionals as outlined by the United States Breastfeeding Committee. According to this committee, all health care professionals should, at a minimum, 1) understand the importance of protecting, promoting, and supporting breastfeeding as a public health priority; 2) provide breastfeeding support; 3) appreciate limitations of their breastfeeding expertise; and 4) know how and when to make a referral to a lactation professional. The tutorial also covered topics related to 5) barriers to breastfeeding, 6) public health professionals' roles in promoting breastfeeding and 7) additional online resources to learn about breastfeeding. As the tutorial focused on public health professionals, who are concerned with population health, several topics such as related to medications and breastfeeding were not addressed in the tutorial. The tutorial was created in an easy-to-read format that was appropriate for graduate level health professionals.

All current Northeastern University MPH Program students and Northeastern University MPH Program alumni represented the pool of potential subjects for the study. The email addresses of all participants were obtained from the MPH program coordinator. Following approval from the Northeastern University institutional review board (IRB), participation requests were sent, via email on November 4, 2011, to 84 participants (58 current students and 26 alumni), followed by two reminder emails 7 days after the initial e-mail invitation and 5 days after the first reminder e-mail. Overall, the potential subjects had 18 days to participate. The email contained the link for the tutorial, the surveys and the description of the project. The link led the subjects to the informed consent page (the first page of the survey) and, once consent was obtained, the participants continued to the pretest, the online tutorial, the post-test, and the attitudinal survey. They could choose to complete the online tutorial and survey at any time.

Two questionnaires using check boxes were used to assess the knowledge of infant feeding practices of health professionals. Three questions in the pre-test covered the baseline knowledge of public health professionals on the following important concepts of infant feeding practices that healthcare professionals must be aware of: 1) The most beneficial form of feeding; 2) the benefits of breastfeeding for infants; and 3) the recommended form of feeding for infants from birth to 6 months. Post-tutorial questions included the three questions in the pretutorial questionnaire, as well as an additional five questions asking about specific important educational topics covered in the tutorial. The purpose of this questionnaire was to assess the gain in knowledge of participants after the tutorial. 
The attitudinal survey was then used to collect information on how MPH students and alumni perceive their roles in helping provide evidence-based information to mothers on breastfeeding. Demographic survey questions were included with the attitudinal survey.

The three questionnaires combined took approximately 5 - 10 minutes to answer. All questions were optional. The tutorial and survey combined took approximately 15 20 minutes to complete. The data were collected in a confidential manner in Word Press software and were anonymous to the researchers. Any results and reports based on this research used only grouped data and did not identify any individual. All research participants were informed that their participation was voluntary and that they may choose to end participation at anytime.

\section{RESULTS}

Out of the 84 potential participants who were contacted, 62\% (44 current and 8 alumni) students provided informed consent and accessed the tutorial. Current MPH students comprised $79 \%$ of the respondents, but represented $70 \%$ of the population invited to participate in the study. A standard binomial test showed no statistical difference between the respondents compared to the source population who were invited to participate $(\mathrm{p}$-value $=$ $0.2524)$.

Out of the fifty-two participants, 49 participants (94\%) completed some part of the pre-tutorial questionnaire, 38 completed the post-tutorial questionnaire (73\%) and 42 participants (81\%) completed some part of the attitudinal survey after the tutorial. Seventy percent of the participants were between the ages of 21 - 26 years. Out of the total responders, $75 \%$ of the subjects reported being White while 25\% comprised all other categories. More than two thirds of the participants were females (87.5\%) based on the demographic data captured in the attitudinal survey. A standard binomial test showed that there was no statistical difference in the sample based on gender compared to the source population who were invited to participate in the research $(\mathrm{p}$-value $=0.3935)$. We did not have age and race data for the source population and were, therefore, unable to compare respondents' characteristics for these variables.

The results of the changes in the fundamental breastfeeding knowledge are shown in Table 3. Out of 46 participants 29 students answered all pre-tutorial questions correctly (63\%) and out of 38 participants who took the post-tutorial questionnaire, 34 students answered all questions correctly (90\%) after the tutorial. There was an overall gain in knowledge as assessed by the improvement in the pre- versus post-tutorial score. Participants' overall correct response ratio improved from the pre$(77 \%)$ to the post-tutorial $(97 \%)$ responses (p-value $=$
Table 3. Results of pre- and post-tutorial questions.

\begin{tabular}{|c|c|c|c|}
\hline $\begin{array}{l}\text { Pre- and } \\
\text { post-tutorial } \\
\text { questions }\end{array}$ & $\begin{array}{c}\text { Pre-tutorial } \\
\mathrm{N}=49 \\
\% \text { Correct }\end{array}$ & $\begin{array}{c}\text { Post-tutorial } \\
\mathrm{N}=38 \\
\% \text { Correct }\end{array}$ & p-value* \\
\hline \multicolumn{4}{|c|}{$\begin{array}{c}\text { Which of the following forms of feeding provides the most } \\
\text { benefits to infants? }\end{array}$} \\
\hline & $93.9 \%$ & $86.8 \%$ & 0.4591 \\
\hline \multicolumn{4}{|c|}{$\begin{array}{l}\text { Which of the following are benefits of breast milk over infant } \\
\text { formula? }^{1}\end{array}$} \\
\hline & $69.3 \%$ & $83.1 \%$ & 0.038 \\
\hline \multicolumn{4}{|c|}{$\begin{array}{l}\text { What is the recommended form of feeding for infants from birth } \\
\text { to } 6 \text { months of age? }\end{array}$} \\
\hline & $81.6 \%$ & $97.4 \%$ & 0.0001 \\
\hline $\begin{array}{l}\text { Overall pre- } \\
\text { and post- } \\
\text { questions }\end{array}$ & $77.0 \%$ & $97.0 \%$ & 0.0001 \\
\hline
\end{tabular}

${ }^{1}$ Multiple benefits of BF were inquired: Reduces risk of infections in the infant, Reduces risk of diabetes in the infant, Reduces risk of Necrotizing Enterocolitis, Reduces risk of cancers in the mother, Saves out-of-pocket costs for the parents, Saves total health care costs through improved health for the infant and mother. ${ }^{\mathrm{p}}$-value comparing the pre and post.

\subsection{1).}

Attitudinal survey results are shown in Table 4. After completion of the online tutorial, the vast majority of MPH students and alumni strongly agreed or agreed that they had an important role in providing advice about meeting the nutritional needs of infants (85\%), and in supporting parents' infant feeding choices (93\%). Almost all students were comfortable answering questions about breastfeeding versus formula feeding as part of their professional responsibilities (92\%). Public health students and alumni most commonly expressed moderate confidence in answering questions parents have on breastfeeding their infants (57\% moderately confident, 37\% extremely or very confident, and $5 \%$ not very or not at all confident) and on introducing solid foods to their infants (47\% moderately confident, $22 \%$ extremely or very confident, and $30 \%$ not very or not at all confident). Overall, males and females responded similarly to survey questions.

\section{DISCUSSION}

While several studies in the past have focused on basic breastfeeding knowledge of health professionals in general, there are no studies focusing specifically on public health students and recent graduates. To our knowledge, this is the first study exploring the attitudes and knowledge of public health students and recent graduates about breastfeeding. This cross-sectional study demonstrated an increase in knowledge about benefits and guidelines of breastfeeding among the participants. The study also demonstrated the knowledge of public health profession- 
Table 4. Results of attitudinal survey.

\begin{tabular}{|c|c|c|c|}
\hline Attitudinal survey $(\mathrm{N}=42)$ & & & \\
\hline & Yes \% & No $\%$ & \\
\hline \multirow{2}{*}{$\begin{array}{l}\text { Are you comfortable answering questions about } \\
\text { breastfeeding vs. infant formula feeding of infants } \\
\text { as part of your professional responsibilities? }\end{array}$} & $92.9 \%$ & $7.1 \%$ & \\
\hline & Strongly agree \% & Agree \% & Neutral \% \\
\hline $\begin{array}{c}\text { "I have an important role in supporting parents' } \\
\text { infant feeding choices" as a public health } \\
\text { professional. }\end{array}$ & $61.5 \%$ & $30.8 \%$ & $7.7 \%$ \\
\hline \multirow[t]{2}{*}{$\begin{array}{l}\text { I have an important role in providing advice about } \\
\text { meeting the nutritional needs of infants. }\end{array}$} & $55.0 \%$ & $30.0 \%$ & $15.0 \%$ \\
\hline & $\begin{array}{l}\text { Extremely confident/ } \\
\text { Very confident } \%\end{array}$ & $\begin{array}{l}\text { Moderately } \\
\text { confident \% }\end{array}$ & $\begin{array}{l}\text { Not very confident/ } \\
\text { Not at all confident \% }\end{array}$ \\
\hline $\begin{array}{l}\text { How confident are you in answering questions } \\
\text { parents have on breastfeeding their infants? }\end{array}$ & $37.5 \%$ & $57.5 \%$ & $5.0 \%$ \\
\hline $\begin{array}{l}\text { How confident are you in answering questions } \\
\text { parents have on introducing solid foods to } \\
\text { their infants? }\end{array}$ & $22.5 \%$ & $47.5 \%$ & $30.0 \%$ \\
\hline
\end{tabular}

als regarding the scenarios when breastfeeding is contraindicated and the barriers to breastfeeding in the US. It also explored what public health professionals felt their roles can be in overcoming these barriers. This study also showed that a vast majority of public health professionals are comfortable in answering questions about breastfeeding versus formula feeding of infants as part of their professional responsibility.

The study had a good response rate of $62 \%$ and the tutorial was found to be effective in improving knowledge about guidelines, benefits, and contraindications of breastfeeding. The participants' confidence with the topic also indicates that improving awareness about a few core concepts can help public health professionals in expanding their professional roles and responsibilities.

The study had some limitations as well. It included a convenient sampling of public health students and recent graduates at Northeastern University. The study also had a small sample size. Also, individual changes in knowledge of health professionals on the pre and the post questionnaires could not be tracked due to anonymous data collection procedures. Another limitation was that most of the students and alumni had high baseline knowledge about breastfeeding as they were exposed to this topic in at least one prior MPH Program class. The study was also unable to determine the average time it took for the participants to read the tutorial or their patterns of the use of the tutorial.

\section{IMPLICATIONS}

Breastfeeding is not widely adopted due to documented barriers and lack of support at a fundamental level [1]. The Surgeon General's report, "Call to Action to Support Breast Feeding” release on January 2011, highlighted the several barriers that exist for mothers who want to breastfeed. These include, lack of adequate knowledge about the importance of breastfeeding, lack of support at home and absence of family members who have experience with breastfeeding, lack of up-to-date breastfeeding information from health care clinicians, inadequate hospital practices (e.g., hospital supplemental feeding with formula, policies and procedures that preclude or inhibit rooming-in, and early discharge often with gift packs including formula), lack of time and privacy to breastfeed or express milk at the workplace along with maternity leave policies, inadequate opportunities to connect with other breastfeeding mothers in the communities and certain cultural beliefs and social norms (e.g., breastfeeding in public) [1].

Moreover, pregnant mothers are constantly barraged with aggressive marketing of infant formula at clinicians' offices. Research shows that prenatal exposure to advertising of human milk substitutes (formula) significantly increases early termination of breastfeeding in the first two weeks and shortens overall duration among women with uncertain breastfeeding goals or goals of twelve weeks of less [23]. Jane Morton, clinical professor of pediatrics at Stanford University School of Medicine and executive board member of the American Academy of Pediatrics' Section on Breastfeeding said that the biggest challenge lies in making breastfeeding, a comfortable, enjoyable, and manageable part of the new mother's life [24].

Numerous reasons to maintain the status quo persist, 
and many social determinants will need to change before we can realize the full benefits of breastfeeding. However, that situation does not prevent us from utilizing every possible existing resource to improve health behaviors at the prenatal, birth, and infancy stages. Health professionals play a major role in influencing breastfeeding. Public health professionals' dynamic role in the community and knowledge of preventive health puts them in a key position to expand their roles in the health promotion and support of breastfeeding as optimal infant feeding. It is very important that public health students are adequately educated on accurate breastfeeding guidelines and on the importance of human lactation. This knowledge will enhance overall health literacy and strengthen their maternal and child public health foundation.

Broader challenges exist related to overcoming the barriers to breastfeeding and improving the low breastfeeding rates in the United States. The lack of health professionals' support for breastfeeding mothers is a major contributor to this situation. To tackle this key public health issue, it is essential for public health professionals to recognize and understand the accurate breastfeeding guidelines and the barriers associated with breastfeeding.

Leveraging an underutilized health resource such as public health professionals to address unmet preventive health needs is especially important in our current health care delivery environment. This pilot study highlights the important role that a short online tutorial can play in expanding public health professionals' knowledge about breastfeeding. Greater use of online methods can enhance awareness of critical health behaviors, such as breastfeeding, that have not received adequate attention in public health curricula.

This pilot study provides the foundation for a larger study and based on the power analysis from results of the current project we need a sample size of 232 subjects before and after the tutorial intervention to have $80 \%$ power for detecting a medium sized effect when employing the traditional $\mathrm{p}<0.05$ criterion of statistical significance. For this larger study we will expand the online tutorial to provide additional information about breastfeeding to hopefully improve MPH students' confidence in answering parents' questions about breastfeeding. We will also administer the attitudinal survey both before and after the online tutorial to evaluate the impact of the tutorial on student's attitudes towards breastfeeding. We are also exploring pathways for creating and disseminating free online continuing education tutorials for public health and breastfeeding professionals. Greater use of online teaching methods also means that this online approach is an essential and an effective tool if we hope to reach existing and future public health pro- fessionals.

\section{CONCLUSION}

When dealing with complex issues associated with inadequate knowledge, social, and cultural barriers, interventional tools such as this on-line breastfeeding tutorial can help assess and improve attitudes of health professionals. Enabling public health professionals to be more effective and to take active roles in tackling fundamental health issues, such as breastfeeding, is essential to achieving our longer-term health goals. Integration of breastfeeding into public health professionals' core training, such as MPH curricula, could support broader social change. Improving breastfeeding practices in US requires a multipronged approach that includes increasing awareness about such an important health behavior coupled with the will and leadership to tackle other social and cultural barriers to breastfeeding faced by mothers.

\section{ACKNOWLEDGEMENTS}

We would like to thank Assistant Professor, Justin Manjourides, PhD and MPH Program Director, Shan Mohammed, MD for their assistance with this project.

\section{REFERENCES}

[1] Grummer-Strawn, L.M. (2012) Surgeon general’s call to action to support breastfeeding: Significant actions in the first year. Breastfeeding Medicine, 7, 332-333. doi:10.1089/bfm.2012.0103

[2] Gartner, L.M., Morton, J., Lawrence, R.A., Naylor, A.J., O’Hare, D., Schanler, R.J. and Eidelman, A.I. (2005) Breastfeeding and the use of human milk. Pediatrics, 115, 496-506. doi:10.1542/peds.2004-2491

[3] Eidelman, A.I. and Schanler, R.J. (2012) Breastfeeding and the use of human milk: An analysis of the American Academy of Pediatrics 2012 Breastfeeding Policy Statement. Breastfeeding Medicine, 7, 323-324. doi:10.1089/bfm.2012.0067

[4] Kruse, L.K., Denk, C.E., Feldman-Winter, L. and Rotondo, F.M. (2005) Comparing socio-demographic and hospital influences on breastfeeding initiation. Birth, 32, 81-85. doi:10.1111/j.0730-7659.2005.00349.x

[5] Shealy, K.R., Li, R., Benton-Davis, S. and GrummerStrawn, L.M. (2005). The CDC guide to breastfeeding interventions. US Department of Health and Human Services, Centers for Disease Control and Prevention, Atlanta.

http://www.cdc.gov/breastfeeding/pdf/breastfeeding_inter ventions.pdf

[6] Dyson, L., Renfrew, M.J., McFadden, A., McCormick, F., Herbert, G. and Thomas, J. (2010) Policy and public health recommendations to promote the initiation and duration of breast-feeding in developed country settings. Public Health Nutrition, 13, 137-144. 


\section{doi:10.1017/S136898000999067X}

[7] Ip, S., Chung, M., et al. (2007) Breastfeeding and maternal and infant health outcomes in developed countries. Evidence Report/Technology Assessment (Full Rep), 153, 1-186.

[8] Zhou, Q., Younger, K.M. and Kearney, J.M. (2010) An exploration of the knowledge and attitudes towards breastfeeding among a sample of Chinese mothers in Ireland. BMC Public Health, 10, 722. doi:10.1186/1471-2458-10-722

[9] Godfrey, J.R. and Lawrence, R.A. (2010) Toward optimal health: The maternal benefits of breastfeeding. Journal of Women's Health, 19, 1597-1602. doi:10.1089/jwh.2010.2290

[10] Gartner, L.M., Morton, J., et al. (2005) Breastfeeding and the use of human milk. Pediatrics, 115, 496-506. doi:10.1542/peds.2004-2491

[11] Dowling, S. and Brown, A. (2012) An exploration of the experiences of mothers who breastfeed long-term: What are the issues and why does it matter? Breastfeeding Medicine, 8, 45-52.

[12] Sobti, J., Mathur, G.P. and Gupta, A. (2002) WHO's proposed global strategy for infant and young child feeding: A viewpoint. Journal of the Indian Medical Association, 100, 502-504, 506.

[13] Centers for Disease Control and Prevention (2009) Breastfeeding report card: United States 2007-2011. Centers for Disease Control and Prevention, Atlanta. Accessed 5 January 2012.

http://www.cdc.gov/breastfeeding/pdf/2009Breastfeeding ReportCard.pdf

[14] Centers for Disease Control and Prevention (US) (2012) Breastfeeding among US children born 2000-2009, CDC National Immunization Survey. http://www.cdc.gov/breastfeeding/data/NIS_data/index.ht $\underline{\mathrm{m}}$

[15] Callen, J. and Pinelli, J. (2004) Incidence and duration of breastfeeding for term infants in Canada, United States, Europe, and Australia: A literature review. Birth, 31, 285-

$$
\text { 292. doi:10.1111/j.0730-7659.2004.00321.x }
$$

[16] US Department of Health and Human Services, Office of Disease Prevention and Health Promotion (2012) Healthy people 2020.

http://www.healthypeople.gov/2020/default.aspx

[17] Creedy, D.K., Cantrill, R.M. and Cooke, M. (2008) Assessing midwives' breastfeeding knowledge: Properties of the Newborn Feeding Ability questionnaire and Breastfeeding Initiation Practices scale. International Breastfeeding Journal, 3, 7. doi:10.1186/1746-4358-3-7

[18] McInnes, R.J. and Chambers, J.A. (2008) Supporting breastfeeding mothers: Qualitative synthesis. Journal of Advanced Nursing, 62, 407-427. doi:10.1111/j.1365-2648.2008.04618.x

[19] Semenic, S., Loiselle, C. and Gottlieb, L. (2008) Predictors of the duration of exclusive breastfeeding among first-time mothers. Research in Nursing \& Health, 31, 428-441. doi:10.1002/nur.20275

[20] Witters-Green, R. (2003). Increasing breastfeeding rates in working mothers. Families, Systems and Health, 21, 415-434. doi:10.1037/h0089617

[21] Cheng, W., Thompson, C.B., Smith, J.A. and Stanley, C. (2003) A web-based breastfeeding education program. The Journal of Perinatal Education, 12, 29-41.

[22] Kahn, G. (1993) Computer-based patient education: A progress report. MD Computing, 10, 93-99.

[23] Howard, C.M., Howard, F., Lawrence, R., Andresen, E., DeBlieck, E. and Weitzman, M. (2000) Office prenatal formula advertising and its effect on breast-feeding patterns. Obstetrics \& Gynecology, 95, 296-303. doi:10.1016/S0029-7844(99)00555-4

[24] Morton, J. and American Academy of Pediatrics (AAP) (2005) AAP policy on breastfeeding and use of human milk.

http://www2.aap.org/breastfeeding/policyOnBreastfeedin gAndUseOfHumanMilk.html 